\section{Site-Specific Fluorescent Labeling of Large RNAs with Pyrene}

RNA molecules that adopt specific folded conformations participate in many biochemical processes. A fundamental description of RNA folding pathways will allow for a more complete understanding of the roles that RNA plays in biochemistry. UNIT 11.8 provides an overview of fluorescence studies of RNA folding, and UNIT 11.10 specifically describes the application of fluorescence resonance energy transfer (FRET) methods. This unit focuses on the preparation of large RNAs - those generally $>80$ nucleotides (nt) in length-with covalently attached pyrene as a fluorescence probe. This approach uses just one chromophore per RNA molecule and is not based on FRET. Typically, the emission intensity of the pyrene chromophore is monitored as a function of solution conditions (e.g., $\mathrm{Mg}^{2+}$ concentration), and these emission intensity measurements are used to infer the populations of various RNA conformational states (Silverman and Cech, 1999b). Although this approach does not provide high-resolution information such as that obtained from synchrotron hydroxyl radical footprinting (UNIT 11.6), fluorescence emission intensity data can provide a simple yet meaningful overview of an RNA folding pathway. Furthermore, such data are generally easy to obtain with common and relatively inexpensive spectrometers, as long as the fluorescently labeled RNAs can be prepared. The specific task of preparing pyrene-labeled RNA is the focus of this contribution.

This unit describes protocols for synthesizing large RNAs that are derivatized with pyrene attached via a short tether at a specific internal nucleotide position. Basic Protocol 1 describes the procedure for pyrene derivatization of the 2 -amino group of a short synthetic RNA oligonucleotide ( $<40 \mathrm{nt}$ in length). This is required as the first step in preparation of large pyrene-labeled RNAs. The second step is to join the pyrene-derivatized oligonucleotide with a second, unlabeled RNA fragment to form the desired full-length RNA. Basic Protocol 2 describes a ligation procedure for this purpose. Basic Protocol 3 describes an annealing procedure to be used when the pyrene-labeled oligonucleotide does not need to be covalently joined to the remainder of the large RNA for it to adopt proper tertiary structure. Each of these protocols has been developed using the pyr3 chromophore shown in Figure 11.11.1 attached at the 2'-position of specific RNA nucleotides (Silverman and Cech, 1999b). This and other pyrene derivatives are useful in terms of fluorescence response when placed at various nucleotides within the P4-P6 domain of the Tetrahymena group I intron RNA (M.K. Smalley and S.K. Silverman, unpub. observ.). The P4-P6 RNA (Cate et al., 1996) has often been used as a test system for studies of RNA folding by fluorescence (Silverman and Cech, 1999b, 2001; Silverman et al., 2000; Young and Silverman, 2002), among other experiments. Pyrene labeling has not yet been studied systematically in large RNAs other than P4-P6. The protocols described here will assist such experiments.

NOTE: For all protocols in this unit, samples should be mixed in the order indicated. After each addition of reagents, the sample tube should be mixed gently (unless otherwise indicated) and microcentrifuged briefly to collect all of the sample at the bottom of the tube. See the note at the beginning of UNIT 11.10 regarding general precautions necessary for working with RNA. Any pyrene-containing samples should be kept away from light as much as possible to avoid photodegradation of the chromophore.
UNIT 11.11

RNA Folding

Pathways

11.11.1

Supplement 19 

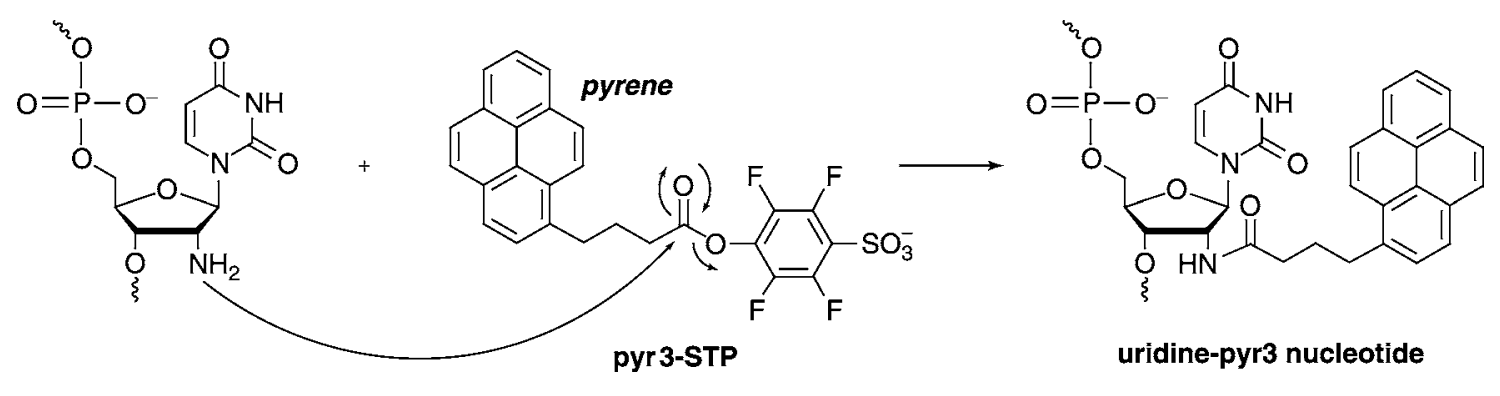

urìdine-pyr3 nucleotîde

Figure 11.11.1 Reaction of the sulfotetrafluorophenyl (STP) ester pyr3-STP with a 2 '-amino group, leading to pyr3derivatized RNA, which is shown as a pyrene-labeled uridine nucleotide.

\section{STRATEGIC PLANNING}

\section{Preparing Pyrene-Labeled RNA Oligonucleotides: Direct Solid-Phase Synthesis Versus Postsynthetic Labeling}

The P4-P6 RNA is $160 \mathrm{nt}$ in length, which is too large to be prepared directly by solidphase synthesis. Therefore, to incorporate a pyrene chromophore at a specific internal position, at least two RNA fragments must be assembled. As shown in Figure 11.11.2A, pyrene is initially incorporated into a smaller portion of the RNA either by solid-phase synthesis using a phosphoramidite monomer (Silverman et al., 2000) or by derivatizing a short RNA oligonucleotide with a suitable reagent such as the sulfotetrafluorophenyl (STP) ester pyr3-STP (Fig. 11.11.1). The latter derivatization procedure is described in Basic Protocol 1.

At present, the only pyrene-labeled nucleotide that is available via a commercial solidphase RNA synthesis service is pyr3-labeled uridine (Fig. 11.11.1), which is offered by Dharmacon (http://www.dharmacon.com; $2^{\prime}$-P-U nucleotide). Dharmacon also provides RNA oligonucleotides containing unlabeled 2 '-amino- $2^{\prime}$-deoxyuridine or $2^{\prime}$-amino- $2^{\prime}$ deoxycytidine; currently, the adenosine and guanosine derivatives are not commercially available. Either of these amino-derivatized nucleotides may be postsynthetically derivatized with pyr3-STP according to Figure 11.11.1 to form pyrene-labeled RNA. It is anticipated that as the pyrene fluorescence method is more widely adopted (e.g., Blount and Tor, 2003), the direct solid-phase synthesis of pyrene-labeled RNA oligonucleotides will become more readily available through commercial sources. In addition, ChemGenes (http://www.chemgenes.com) offers the pyrimidine 2 -amino-2'-deoxynucleotide phosphoramidite monomers for solid-phase RNA synthesis by individual investigators.

\section{Assembling a Large Pyrene-Labeled RNA: Ligation Versus Annealing}

Once a pyrene-labeled RNA oligonucleotide is in hand, it can be used in the assembly of a large RNA. For P4-P6, two assembly approaches have been reported: ligation (Silverman and Cech, 1999b) and annealing (Golden et al., 1996). In the ligation approach, the short pyrene-labeled RNA oligo is covalently joined using T4 DNA ligase to a second RNA fragment that encompasses the remaining nucleotides of P4-P6 (Fig. 11.11.2B; Basic Protocol 2). Alternatively, in the annealing approach, the ligation reaction is omitted because the short oligonucleotide bearing the pyrene label can hybridize noncovalently with the remainder of the RNA, as shown schematically in Figure 11.11.2C. After the derivatization, the annealing step of Basic Protocol 3 is performed, using a modest excess of the unlabeled RNA to ensure that all of the labeled RNA becomes part of a full-length

Site-Specific

Fluorescent Labeling of Large RNAs with Pyrene

11.11.2
RNA complex. 


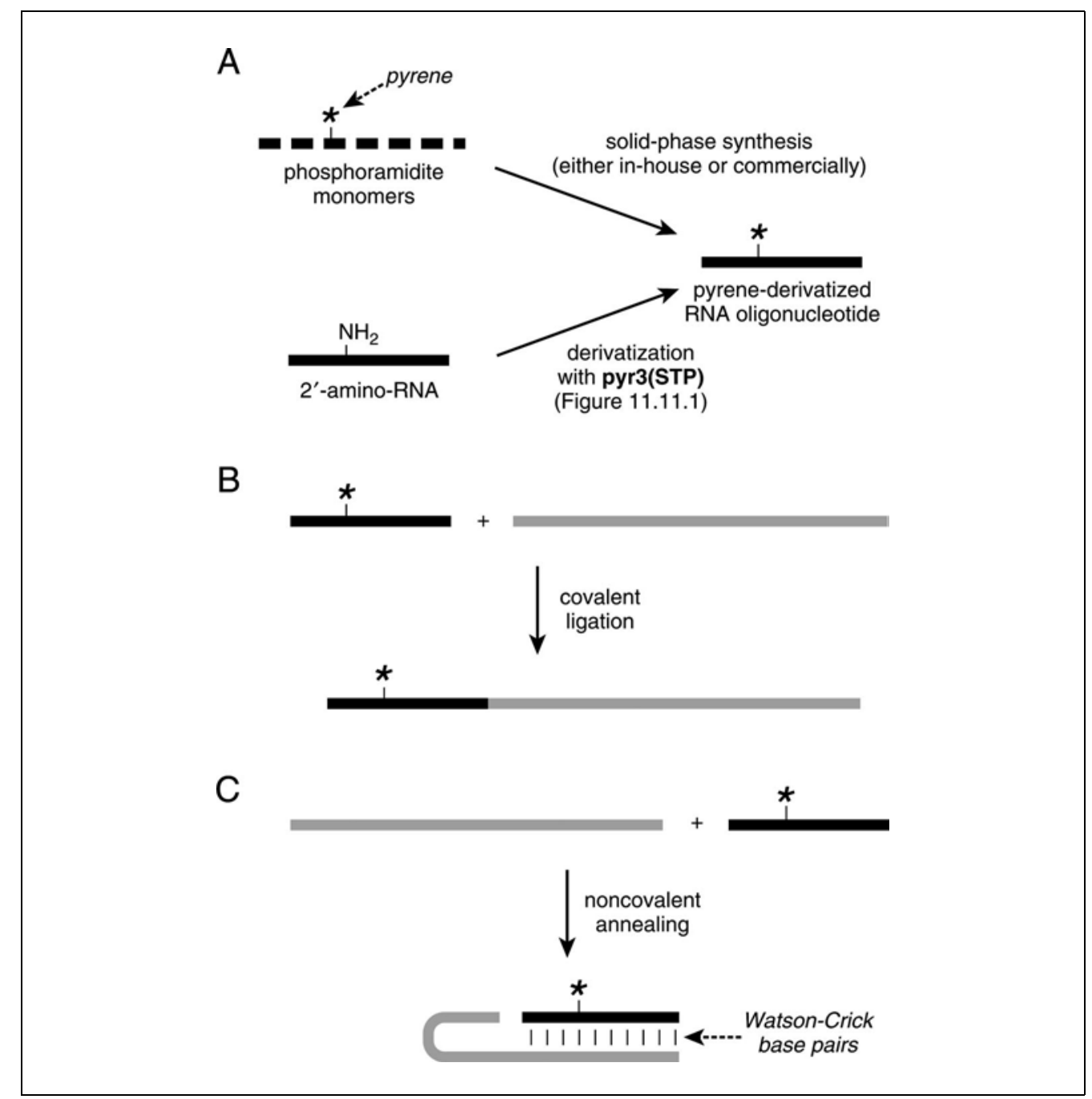

Figure 11.11.2 Synthetic approaches for large pyrene-labeled RNAs. (A) Preparing a short pyrene-labeled RNA oligonucleotide either by solid-phase synthesis or by derivatizing a 2'-aminoRNA with pyr3-STP (Basic Protocol 1). (B) Covalently ligating the short pyrene-labeled RNA to form a full-length labeled RNA (Basic Protocol 2). (C) Noncovalently annealing the short pyrenelabeled RNA to the remainder of the large RNA to form full-length RNA without ligation (Basic Protocol 3).

The ligation procedure of Basic Protocol 2 is required when the RNA backbone must be intact. In contrast, if a nick in the backbone is tolerated-that is, if the RNA fragment bearing the pyrene chromophore does not have to be covalently joined to the remainder of the RNA for proper structure - then the procedure of Basic Protocol 2 is unnecessary, and Basic Protocol 3 is performed instead. The choice of assembly strategies will be determined by the specific requirements of the large RNA being studied, as discussed in the Commentary (see Critical Parameters).

\section{DERIVATIZATION OF A 2'-AMINO RNA OLIGONUCLEOTIDE WITH PYRENE}

Derivatizing the RNA oligonucleotide with pyrene requires that the RNA have an appropriately reactive 2 -amino group and that a suitably activated pyrene reagent be available. This protocol describes the use of pyr3-STP to derivatize a $2^{\prime}$-amino group, forming a pyr3-labeled RNA oligonucleotide, as shown in Figure 11.11.1. If the pyrene-labeled RNA is obtained directly from solid-phase synthesis, then most of Basic Protocol 1 is not necessary, and the preparation can be continued with Basic Protocol 2 or Basic Protocol 3 
as appropriate. In all cases, however, the oligonucleotide should be purified by denaturing polyacrylamide gel electrophoresis as described below.

\section{Materials}

RNA oligonucleotide with a 2 '-amino group

$500 \mathrm{mM}$ sodium phosphate buffer, $\mathrm{pH} 8.0$ (APPENDIX 2A)

10 mM EDTA, pH 8.0 (APPENDIX 2A)

$50 \mathrm{mM}$ pyrene 4-sulfotetrafluorophenyl ester (pyr3-STP; Molecular Probes or Gee et al., 1999) in $N, N$-dimethylformamide (DMF)

$3 \mathrm{M} \mathrm{NaCl}$ (prepared directly or diluted from $5 \mathrm{M} \mathrm{NaCl}$; see APPENDIX 2A)

Absolute ethanol (e.g., Fisher)

$80 \%$ formamide gel loading buffer with dye (see recipe)

TEN buffer (see recipe)

1.7-mL RNase-free microcentrifuge tubes (e.g., Eppendorf or Fisher)

Speedvac evaporator (Savant)

Glass rod

50-mL plastic tube (e.g., Fisher)

Platform rocker (Clay-Adams Nutator or equivalent)

$0.45-\mu \mathrm{m}$ syringe filter (e.g., Fisher)

40-mL polypropylene tube (e.g., Oak Ridge tube from Fisher)

Tabletop centrifuge (e.g., IEC HN-SII), chilled to $4^{\circ} \mathrm{C}$

Refrigerated centrifuge (e.g., Beckman J2-HS with Beckman JS-13.1 rotor)

Additional reagents and equipment for denaturing polyacrylamide gel

electrophoresis (PAGE; APPENDIX 3B)

\section{Derivatize oligonucleotide}

1. Dissolve the $2^{\prime}$-amino-RNA in water to make a $500 \mu \mathrm{M}$ solution.

This RNA may be obtained either from a commercial supplier or by solid-phase synthesis in an individual laboratory (see Strategic Planning).

2. Combine the following in a $1.7-\mathrm{mL}$ microcentrifuge tube (total $125 \mu \mathrm{L}$ ):

$20 \mu \mathrm{L} 500 \mu \mathrm{M}$ RNA from step $1(10 \mathrm{nmol})$

$50 \mu \mathrm{L} 500 \mathrm{mM}$ sodium phosphate buffer, $\mathrm{pH} 8.0$

$5 \mu \mathrm{L} 10 \mathrm{mM}$ EDTA, $\mathrm{pH} 8.0$

$50 \mu \mathrm{L} \mathrm{H}_{2} \mathrm{O}$.

If the RNA stock solution is at a concentration other than $500 \mu \mathrm{M}$, adjust the amount of water accordingly.

3. Add $125 \mu \mathrm{L}$ of $50 \mathrm{mM}$ pyr3-STP in DMF, and incubate the resulting clear solution at room temperature for $24 \mathrm{hr}$.

The final concentrations during incubation are $40 \mu M$ RNA, $100 \mathrm{mM}$ sodium phosphate, $0.2 \mathrm{mM}$ EDTA, $25 \mathrm{mM}$ pyr3-STP, and 50\% (v/v) DMF.

4. Remove $125 \mu \mathrm{L}$ of the $250-\mu \mathrm{L}$ sample to a second $1.7-\mathrm{mL}$ microcentrifuge tube. To each tube add $175 \mu \mathrm{L}$ water, to a total volume of $300 \mu \mathrm{L}$.

5. To each tube add $30 \mu \mathrm{L}$ of $3 \mathrm{M} \mathrm{NaCl}$ and $900 \mu \mathrm{L}$ absolute ethanol, and vortex the sample for $10 \mathrm{sec}$. Freeze the samples on dry ice for at least $20 \mathrm{~min}$ or in a $-80^{\circ} \mathrm{C}$ freezer for at least $1 \mathrm{hr}$.

Site-Specific

Fluorescent Labeling of Large RNAs with Pyrene

\subsection{4}


7. Remove the supernatants with a micropipettor and dry the pelleted samples in a Speedvac evaporator for $5 \mathrm{~min}$. Redissolve each pellet in $50 \mu \mathrm{L}$ water and combine the two samples.

\section{Purify derivatized RNA}

8. To the $100-\mu \mathrm{L}$ sample, add $250 \mu \mathrm{l}$ of $80 \%$ formamide gel loading buffer with dye. Purify the sample by denaturing PAGE (APPENDIX $3 B$ ) on a $20 \%$ gel that is $3 \mathrm{~mm}$ thick on $26 \times 20-\mathrm{cm}$ glass plates. Use one lane of a three-lane gel for a single derivatization sample. Set the power supply at $30 \mathrm{~W}$ and electrophorese the sample for 4 to $5 \mathrm{hr}$.

9. Excise the band that corresponds to the derivatized RNA (see gel purification method in UNIT 11.10).

The desired band migrates slightly more slowly than the band corresponding to underivatized RNA (see Commentary).

10. Manually crush the excised gel band with a glass rod in a 50-mL plastic tube.

11. To extract the RNA, add 6 to $7 \mathrm{~mL}$ TEN buffer and place the sample tube on a platform rocker at $4{ }^{\circ} \mathrm{C}$ for 6 to $12 \mathrm{hr}$. Centrifuge the sample at least $10 \mathrm{~min}$ at $200 \times g(1000 \mathrm{rpm}$ in IEC HN-SII $), 4^{\circ} \mathrm{C}$, and filter through a $0.45-\mu \mathrm{m}$ syringe filter into a 40-mL polypropylene tube.

12. Extract again as in step 11 and combine the two extracts for a total eluted volume of $10 \mathrm{~mL}$.

The extraction will require a total of $\sim 12$ to $13 \mathrm{~mL}$ of TEN buffer, of which 2 to $3 \mathrm{ml}$ remains absorbed into the polyacrylamide pellet and is unrecoverable.

13. Add $27 \mathrm{~mL}$ cold absolute ethanol to the combined TEN elutions and place the sample at $-20^{\circ} \mathrm{C}$ for at least $6 \mathrm{hr}$.

14. Precipitate the RNA by centrifuging 30 min at $\sim 10,000 \times g(8000 \mathrm{rpm}$ in Beckman JS-13.1 rotor), $4^{\circ} \mathrm{C}$.

15. Wash the pellet by adding $1 \mathrm{ml}$ cold $75 \%$ ethanol, centrifuging $10 \mathrm{~min}$ as in step 14 , and removing the ethanol by pipetting. Dry under vacuum for $10 \mathrm{~min}$. Dissolve sample in $300 \mu \mathrm{L}$ water and quantitate by UV absorbance $\left(A_{260}\right)$.

A typical isolated yield of derivatized RNA is 3 to $5 \mathrm{nmol}$ starting from $10 \mathrm{nmol}$ at step 1 .

\section{ASSEMBLY OF THE LARGE RNA BY LIGATION}

When the full-length RNA must be assembled using covalent ligation (Fig. 11.11.2B), this protocol is used. Ligation is performed using T4 DNA ligase and a complementary DNA splint that extends for at least ten nucleotides on either side of the ligation junction (Moore and Sharp, 1992; Moore and Query, 1998; Silverman and Cech, 1999a). Because yields from such splint ligation reactions can vary widely, optimization is necessary (see Commentary).

\section{Materials}

PAGE-purified pyrene-derivatized RNA oligonucleotide (see Basic Protocol 1)

DNA splint oligonucleotide (e.g., Integrated DNA Technologies or other commercial supplier)

Polynucleotide that constitutes the remaining portion of the large RNA (e.g., transcribed from a plasmid DNA template, as described in Silverman and Cech, 1999a)

$10 \times$ annealing buffer (see recipe)

$10 \times$ ligation buffer (see recipe)

RNA Folding

Pathways

11.11.5 
T4 DNA ligase (e.g., USB; see Commentary)

$80 \%$ formamide gel loading buffer with dye (see recipe)

1.7-mL RNase-free microcentrifuge tubes (e.g., Eppendorf or Fisher)

Dry heating block

Additional reagents and equipment for denaturing polyacrylamide gel

electrophoresis (PAGE; APPENDIX 3B)

1. Place $2.0 \mathrm{nmol}$ of pyrene-derivatized RNA oligonucleotide into a $1.7-\mathrm{mL}$ microcentrifuge tube.

2. Add $3.0 \mathrm{nmol}(1.5 \mathrm{eq})$ of the DNA splint and $3.2 \mathrm{nmol}(1.6 \mathrm{eq})$ of the polynucleotide that constitutes the remaining portion of the large RNA. Evaporate the sample to dryness on a Speedvac evaporator and redissolve in $90 \mu \mathrm{l}$ water.

Alternatively, if the sample volume after mixing all components is less than $90 \mu \mathrm{L}$, omit the evaporation step and add sufficient water to raise the sample volume to $90 \mu \mathrm{L}$. Lower yields of RNA ligation are observed if an excess of the DNA splint and RNA polynucleotide is not used (see Commentary).

3. Add $10 \mu \mathrm{l}$ of $10 \times$ annealing buffer. Anneal the sample by heating in a dry heating block to $95^{\circ} \mathrm{C}$ for $3 \mathrm{~min}$ and cooling on ice for $5 \mathrm{~min}$.

4. Equilibrate the sample by heating in a water bath at $37^{\circ} \mathrm{C}$ for $2 \mathrm{~min}$.

5. Add $12.5 \mu \mathrm{l}$ of $10 \times$ ligation buffer followed by $12.5 \mu \mathrm{L}$ of T4 DNA ligase. Incubate the sample in a water bath at $37^{\circ} \mathrm{C}$ for $4 \mathrm{hr}$.

6. Add $200 \mu \mathrm{l}$ of $80 \%$ formamide gel loading buffer with dye. Purify the sample by denaturing PAGE (APPENDIX $3 B$ ) on a $12 \%$ gel that is $1.5 \mathrm{~mm}$ thick on $26 \times 20-\mathrm{cm}$ glass plates. Use one lane of a three-lane gel for a single ligation sample. Set the power at $30 \mathrm{~W}$ and electrophorese the sample for 7 to $8 \mathrm{hr}$.

The separation between unligated and ligated RNA must be optimized depending on the exact sizes of the RNAs (see Commentary).

7. Excise the band that corresponds to the ligated RNA (see gel purification method in UNIT 11.10) and extract and precipitate the RNA (see Basic Protocol 1, steps 9 to 15).

A typical isolated yield of ligated RNA is 0.5 to $0.8 \mathrm{nmol}$ starting from $2.0 \mathrm{nmol}$ at step 1 .

8. Proceed to the fluorescence experiments using the RNA sample.

BASIC PROTOCOL 3

Site-Specific

Fluorescent Labeling of Large RNAs with Pyrene

11.11.6

\section{ASSEMBLY OF THE LARGE RNA BY ANNEALING}

When the full-length RNA can be assembled by noncovalently hybridizing the pyrenelabeled fragment to the remainder of the RNA (Fig. 11.11.2C), this protocol is used. As for most annealing procedures, this protocol should not be followed until fluorescence experiments are ready to be performed on the annealed sample (see UNIT 11.8). Typically, an excess of the unlabeled RNA relative to pyrene-labeled RNA is used. This ensures that all of the pyrene label is found within a full-length RNA assembly.

\section{Materials}

PAGE-purified pyrene-derivatized RNA oligonucleotide (see Basic Protocol 1)

Polynucleotide that constitutes the remaining portion of the large RNA (e.g., transcribed from a plasmid DNA template, as described in Silverman and Cech, 1999a)

$10 \times$ TB buffer (equivalent to $10 \times$ TBE but omitting EDTA; see APPENDIX 2A)

1.7-mL RNase-free microcentrifuge tubes (e.g., Eppendorf or Fisher)

Dry heating block 
1. Place $0.2 \mathrm{nmol}$ of the pyrene-derivatized RNA oligonucleotide from Basic Protocol 1 into a $1.7-\mathrm{mL}$ microcentrifuge tube.

2. Add $0.8 \mathrm{nmol}(4 \mathrm{eq})$ of the polynucleotide that constitutes the remaining portion of the large RNA.

3. Add sufficient water to obtain a total volume of $603 \mu \mathrm{L}$.

4. Add $67 \mu \mathrm{L}$ of $10 \times \mathrm{TB}$ buffer, providing a total sample volume of $670 \mu \mathrm{L}$ in $1 \times \mathrm{TB}$ buffer.

5. Anneal the sample by heating to $60^{\circ} \mathrm{C}$ for $10 \mathrm{~min}$ in a dry heating block and cooling at room temperature on the benchtop for $10 \mathrm{~min}$.

This volume of sample is sufficient to provide at least $650 \mu \mathrm{L}$ for transfer to a standard fluorescence cuvette. The heating temperature during annealing is kept down to $60^{\circ} \mathrm{C}$ to avoid nonspecific RNA degradation.

EDTA is omitted from the sample during this process, because fluorescence experiments often involve addition of small amounts of $\mathrm{Mg}^{2+}$ as part of a detailed titration series (Silverman and Cech, 1999b). The buffer used may be varied (see Commentary).

6. Proceed to the fluorescence experiments using the RNA sample.

\section{REAGENTS AND SOLUTIONS}

Use deionized RNase-free water in all recipes and protocol steps. Do not use DEPC-treated water (see UNIT 11.10 for precautions to avoid RNase contamination). For common stock solutions, see APPENDIX 2A. For suppliers, see SUPPLIERS APPENDIX.

\section{$10 \times$ annealing buffer}

$50 \mu \mathrm{L} 1 \mathrm{M}$ Tris. $\mathrm{Cl}, \mathrm{pH} 7.5$ (APPENDIX $2 \mathrm{~A} ; 50 \mathrm{mM}$ final)

$2 \mu 10.5$ M EDTA, pH 8.0 (APPENDIX 2A; $1 \mathrm{mM}$ final)

Dilute to $1 \mathrm{~mL}$ with $\mathrm{H}_{2} \mathrm{O}$

Store up to 1 year at room temperature

\section{Formamide gel loading buffer with dye (80\% formamide)}

Place $25 \mathrm{mg}$ each of xylene cyanol and bromphenol blue into an autoclaved 125 -mL glass bottle. Add $80 \mathrm{~mL}$ formamide (e.g., Fisher), $10 \mathrm{~mL} \mathrm{10 \times} \mathrm{TBE}$ buffer, and $10 \mathrm{~mL} 0.5 \mathrm{M}$ EDTA (see APPENDIX $2 A$ for the latter two reagents). Swirl the components to mix completely. Do not autoclave, which will decompose the formamide. Store up to 1 year at $4^{\circ} \mathrm{C}$.

\section{Ligation buffer, $10 \times$}

$500 \mu \mathrm{L} 1 \mathrm{M}$ Tris.Cl, pH 8.0 (APPENDIX 2A; $500 \mathrm{mM}$ final)

$100 \mu \mathrm{L} 1 \mathrm{M} \mathrm{MgCl}_{2}(100 \mathrm{mM}$ final $)$

$300 \mu \mathrm{L} 250 \mathrm{mM}$ dithiothreitol (DTT; $75 \mathrm{mM}$ final)

$100 \mu \mathrm{L} 100 \mathrm{mM}$ ATP (10 mM final)

Store up to 1 year at $-20^{\circ} \mathrm{C}$ (avoid repeated freeze-thaw cycles, which may decompose the ATP)

\section{TEN (Tris/EDTA/NaCl) buffer}

$4 \mathrm{~mL} 1 \mathrm{M}$ Tris.Cl, pH 8.0 (APPENDIX 2A; $10 \mathrm{mM}$ final)

$800 \mu \mathrm{L} 0.5 \mathrm{M}$ EDTA, pH 8.0 (APPENDIX 2A; $1 \mathrm{mM}$ final)

$40 \mathrm{~mL} 3 \mathrm{M} \mathrm{NaCl}$ (or $24 \mathrm{~mL} 5 \mathrm{M} \mathrm{NaCl}$; APPENDIX $2 A ; 300 \mathrm{mM}$ final)

Dilute to $400 \mathrm{~mL}$ with $\mathrm{H}_{2} \mathrm{O}$

Sterilize by autoclaving

Store up to 1 year at room temperature

RNA Folding

Pathways

11.11.7 


\section{COMMENTARY}

\section{Background Information}

Fluorescence methods are widely used throughout biochemistry to monitor conformational changes (Whitaker, 2000; Mollova, 2002). In particular, fluorescence approaches have been employed in many cases with RNA. The 2-aminopurine nucleobase is often used (Millar, 1996), but the fluorescence changes upon RNA folding are frequently small; the responses are largest when the nucleobase changes its stacking during the RNA folding event. Several reports have demonstrated that pyrene is a useful probe of RNA tertiary structure. In principle, a pyrene chromophore may be incorporated at either the $5^{\prime}$-terminus (Bevilacqua et al., 1992; Kierzek et al., 1993) or 3'-terminus (see Chapter 4 for terminal modifications of oligonucleotides). Alternatively, pyrene may be incorporated at an internal nucleotide position (Silverman and Cech, 1999b, 2001; Silverman et al., 2000; Young and Silverman, 2002; Blount and Tor, 2003). Although site-specific labeling at a terminus is generally possible for any RNA sequence, each RNA necessarily has many more internal positions than termini. These internal positions offer greater opportunity for monitoring different phases of RNA folding depending on the location of the chromophore. Circular permutation (Pan and Uhlenbeck, 1993; Pan, 2000) can convert an internal RNA position into a terminus, thereby overcoming this limitation. However, some sites of interest for derivatization will require maintaining the local backbone connectivity for proper RNA structure, and thus these positions are unsuitable for the circular permutation approach. This necessitates an assembly strategy in which the chromophore is incorporated internally into the large RNA.

The assembly strategies shown in Figure 11.11.2 are in principle applicable to any large RNA. However, several practical issues must be addressed. First, solid-phase RNA synthesis has a limit ( $\sim 80 \mathrm{nt})$ that is much smaller than many large RNAs, which may have up to several hundred nucleotides. Therefore, the major challenge in preparing large site-specifically modified RNAs is the assembly of multiple RNA fragments, one or more of which have nonstandard nucleotides. This assembly requires either the ligation or annealing strategy of Figure 11.11.2B or C, depending on whether or not the RNA tolerates a break in the backbone at the chosen location (see Critical Parameters). Second, if the site of chro- mophore incorporation is not near one of the termini, and therefore the short pyrene-labeled RNA oligonucleotide lies near the middle of the large RNA, multiple ligation reactions may be necessary to prepare the full-length modified RNA. Although numerous ligations can be performed sequentially, the final yields necessarily suffer (Silverman and Cech, 1999a). Fluorescence experiments require sufficiently large amounts of pyrene-labeled RNA (typically nanomoles) that multiple ligations are to be avoided whenever possible. The fluorescence experiments reported to date that use RNA ligation require just one ligation reaction to provide properly folded RNA.

Once a reasonable synthesis strategy has been designed and the pyrene-labeled RNA has been prepared, either equilibrium titration or stopped-flow experiments may be performed (Bevilacqua et al., 1992; Kierzek et al., 1993; Silverman and Cech, 1999b, 2001; Silverman et al., 2000; Young and Silverman, 2002). It is also possible to monitor other fluorescence characteristics of the pyrene, such as its fluorescence lifetime and anisotropy (Preuss et al., 1997; Walter et al., 1998). The protocols described in this unit should facilitate applying these methods to an increasing array of interesting large RNA structures.

\section{Critical Parameters}

\section{RNA derivatization with pyrene}

The derivatization method described in Basic Protocol 1 has been optimized for the specific reaction shown in Figure 11.11.1. The reactions used a 15-mer 2'-amino-modified oligonucleotide corresponding to the first 15 nt of P4-P6, in which the $2^{\prime}$-amino group was on U107, the sixth nucleotide from the $5^{\prime}$-end. In the initial report (Silverman and Cech, 1999b), an $N$-hydroxysuccinimide (NHS) ester was used as the activated pyrene reagent; subsequently, the more water-soluble 4-sulfotetrafluorophenyl (STP) ester (Gee et al., 1999) was found to provide faster labeling with higher yield (M.K. Smalley and S.K. Silverman, unpub. observ.). For individual small-scale reactions, purchasing the pyr3STP reagent is likely the most expedient option. For larger-scale reactions or for multiple derivatizations, preparing the reagent according to the published procedure (Gee et al., 1999) would be worthwhile.

The authors have also found that a 24mer 2'-amino-modified oligonucleotide corresponding to the last $24 \mathrm{nt}$ of P4-P6 
(Golden et al., 1996) may be derivatized successfully under the same conditions when the $2^{\prime}$-amino-nucleotide is located at various sites within the 24-mer. For unrelated $2^{\prime}$-aminoRNAs that would be required for other large RNAs, the derivatization efficiency should be checked by analytical-scale assays before committing a large amount of material to the procedure. The variables to adjust include the buffer identity and $\mathrm{pH}$ (sodium phosphate, $\mathrm{pH} 7$ to 8 , or bicine, $\mathrm{pH} 8$ to 9 ), reaction temperature $\left(16^{\circ}\right.$ to $\left.60^{\circ} \mathrm{C}\right)$, and incubation time (1 to $24 \mathrm{hr}$ ). To facilitate the quantification of these assays, a small portion of the oligonucleotide should be $5^{\prime}{ }^{32} \mathrm{P}$-radiolabeled (e.g., UNITS $6.1 \& 10.4$ ), which permits the assay to be monitored using analytical-scale PAGE and a PhosphorImager (Silverman and Cech, 1999b).

An important concern in the derivatization protocol is the extent of nonspecific labeling of various nucleophilic sites on the oligonucleotide other than the $2^{\prime}$-amino group. The extent of nonspecific labeling may be assessed by performing the derivatization reaction on an unmodified oligonucleotide that has the same RNA sequence but lacks the 2 '-amino group. For the unmodified 15-mer oligonucleotide corresponding to the first 15 nt of P4-P6, nonspecific labeling occurs to the extent of $5 \%$ to $8 \%$ under the conditions of Basic Protocol 1. This is compared with specific labeling to the extent of $\sim 75 \%$ for an RNA oligonucleotide of the same sequence with a single $2^{\prime}$-amino group.

To avoid decomposition, small aliquots of pyr3-STP stock solution $(<100 \mu \mathrm{L})$ should be stored in a $-80^{\circ} \mathrm{C}$ freezer and kept on ice when not in immediate use. If the derivatization reaction is unsuccessful, then the purity of the pyr3-STP should be checked by thin-layer chromatography (APPENDIX 3D), and the sample should be discarded or repurified by silica gel column chromatography (APPENDIX $3 E$ ) as necessary.

\section{RNA ligation}

The yields of T4 DNA ligase-mediated splint ligations vary widely depending on the exact sequence and structural context of the ligation site. Therefore, for any new RNA ligation, the efficiency must be optimized on a small scale using ${ }^{32} \mathrm{P}$-radiolabeled samples as required. The ratio of the two RNA fragments and the DNA splint are generally chosen such that one RNA fragment is the limiting reagent and the other two nucleic acids are in modest excess (a 1:1:1 ratio of the three components usually gives poor results). The amounts and ratios reported in Basic Protocol 2 were chosen based on empirical data, with the consideration that the pyrene-derivatized RNA oligonucleotide is typically the most precious of the three fragments and is therefore the limiting reagent.

Despite significant optimization attempts, it is sometimes the case that a particular splint ligation cannot be achieved in high yield (e.g., Sontheimer et al., 1999; Strobel and OrtolevaDonnelly, 1999). If so, the most expedient strategy may be to redesign the experiment to avoid that particular ligation site, because moving the ligation site by even just one nucleotide can have an unpredictable and often substantial effect on the ligation efficiency. Ongoing efforts with deoxyribozymes (Flynn-Charlebois et al., 2003) may alleviate some of the difficulties associated with T4 DNA ligase-mediated splint ligations.

Several commercial suppliers provide T4 DNA ligase. However, the enzyme from some sources may be ineffective owing to insufficient degree of purification or insufficient concentration. Because the availability of T4 DNA ligase from various manufacturers changes with time, this must be tested empirically. The authors generally use $\mathrm{His}_{6}$-tagged T4 DNA ligase prepared in-house from a plasmid clone provided by Scott Strobel (Yale University). The amount of T4 DNA ligase required for a specific scale of ligation reaction is optimized for each batch of enzyme.

After the ligation reaction has been performed, the sample is purified by denaturing PAGE (APPENDIX 3B). The percentage of acrylamide and the running time must be optimized for each ligation reaction, depending on the sizes of the unligated and ligated RNA. Generally, because the pyrene-derivatized fragment is a relatively short oligonucleotide $(<40 \mathrm{nt})$ and the remainder of the RNA is often very large (>100 nt), the physical separation on the gel between unligated and ligated RNA may be small. For ligation of the pyrene-derivatized 15-mer oligonucleotide to the 145-mer corresponding to the remainder of P4-P6 (Silverman and Cech, 1999a,b), the observed separation requires a higher-than-usual percentage of acrylamide (12\%) for that length of RNA, and consequently a longer running time ( $\sim 7$ to $8 \mathrm{hr}$ for a 1.5-mm-thick gel). For a lower percentage of acrylamide (e.g., 6\%), which would be more typical for such a large RNA, the separation between unligated and ligated RNA is insufficient on a preparative scale. For RNAs other than P4-P6, the details of the electrophoresis
RNA Folding

Pathways

11.11.9 
must be determined empirically to identify adequate separation conditions.

After preparing a sample by ligation according to Basic Protocol 2 and before fluorescence spectroscopy, one can consider whether a renaturation (annealing) step is necessary (see UNIT 11.8). At this point, the annealing procedure of Basic Protocol 3 may be performed if desired. For P4-P6, the authors have performed fluorescence experiments both with and without a renaturation step. In equilibrium fluorescence experiments the authors have observed indistinguishable results, and typically do not renature the sample for this purpose. However, for stopped-flow fluorescence experiments, modest differences in kinetics have been observed, so it would be reasonable to renature the sample before performing the experiments. In general, the need for renaturation after ligation should be checked experimentally, and the renaturation may be omitted if it is shown to be unnecessary.

\section{RNA annealing}

The Tris-borate buffer reported for annealing in Basic Protocol $3(1 \times$ TB) is the same as that typically used for nondenaturing gel electrophoresis of structured RNAs (Silverman and Cech, 1999a). This buffer has also proven to be suitable for pyrene fluorescence spectroscopy, although various buffer identities and strengths are acceptable (Silverman and Cech, 1999b). For other large RNAs, the effects of buffer composition on fluorescence spectroscopy should be tested explicitly, as bufferdependent differences in folding rates have been observed (Silverman et al., 2000).

In the annealing procedure, the heating temperature should be high enough to denature any undesired RNA secondary structures that might be present, but it should not be so high that nonspecific RNA degradation is promoted. The annealing buffer does not contain EDTA to chelate any stray divalent metal ions that may be present, because EDTA may interfere with $\mathrm{Mg}^{2+}$ titrations during subsequent fluorescence experiments. Therefore, the commonly used annealing temperature of $90^{\circ}$ to $95^{\circ} \mathrm{C}$ (in the presence of EDTA; e.g., Basic Protocol 2, step 3) is unwise in this context because any trace amount of a divalent ion such as $\mathrm{Ca}^{2+}$ could lead to degradation during the heating step. The temperature of $60^{\circ} \mathrm{C}$ reported in Basic Protocol 3 is a compromise between the need to denature and the need to avoid degradation. For other large RNAs, the heating temperature required for reproducible results must be determined empirically.

\section{Choice of site to derivatize the RNA with pyrene}

The choice of a specific nucleotide to be labeled with pyrene according to Figure 11.11.1 may be guided by available X-ray crystallography or NMR spectroscopy data. For example, the X-ray crystal structure of P4-P6 (Cate et al., 1996) allowed sites for 2 '-derivatization to be chosen in a rational manner (Silverman and Cech, 1999b; M.K. Smalley and S.K. Silverman, unpub. observ.). These results have led to the general prediction that many sites within other large RNAs should be good candidates for modification, even without guidance from high-resolution structural information. If the large RNA of interest has no highresolution structure available, then a reasonable strategy is to choose multiple sites and prepare several pyrene-labeled versions of the RNA in parallel. An appropriate structural or functional assay (e.g., nondenaturing gel electrophoresis or catalytic activity) should then be performed to determine if the pyrene derivatizations have disrupted the RNA structure significantly. Only those pyrene-labeled RNAs that function well in the appropriate assay should be pursued further using fluorescence experiments.

\section{Choice of site(s) to divide the RNA for assembly}

Each of the two strategies of Figure 11.11.2 requires choosing at least one site at which to divide the RNA. If the derivatization site is very close to the ligation junction (Fig. 11.11.2B), then T4 DNA ligase-mediated joining of the two RNA fragments may not work well. This problem is observed when a pyr 3 modification is included merely three nucleotides from the ligation site within P4-P6 (M.K. Smalley and S.K. Silverman, unpub. observ.). Because the success of splint ligation is difficult to predict as described above, it is best to avoid designing a ligation site very close to the derivatization site. Regardless of the location of the ligation site, the ligation efficiency should be checked on the analytical scale using ${ }^{32} \mathrm{P}$-radiolabeled RNAs before committing large amounts of material to preparative reactions. Alternatively, if the annealing strategy of Figure $11.11 .2 \mathrm{C}$ can be used instead of ligation, then this obviates the issue of derivatization interfering with ligation.

\section{Anticipated Results}

Once tractable derivatization and ligation or annealing conditions are established, synthesis of pyrene-labeled RNA is usually 
uneventful. Starting from $10 \mathrm{nmol}$ of unlabeled 2 -amino oligonucleotide and assuming average yields of derivatization and ligation, $\sim 1$ to $2 \mathrm{nmol}$ of pyrene-labeled RNA is expected. At a concentration of $300 \mathrm{nM}$, which is typical for equilibrium fluorescence studies, this is sufficient for three to six experiments. Stoppedflow experiments require more material, and the preparative reactions may need to be scaled up several-fold. Typical results from both equilibrium and stopped-flow fluorescence experiments using pyrene-labeled P4-P6 are found in the published papers of the authors (Silverman and Cech, 1999b, 2001; Silverman et al., 2000; Young and Silverman, 2002).

\section{Time Considerations}

Once the appropriate 2'-amino RNA oligonucleotide(s) and pyr3-STP are in hand, testing the derivatization reaction typically takes several days. Testing the ligation reactions should require a similar length of time, although several testing rounds may be needed to find suitable sites. Finally, assaying the derivatized and ligated RNA in structural or functional assays may take several additional weeks. Once appropriate derivatization and (if necessary) ligation sites have been identified, then equilibrium or stopped-flow fluorescence experiments may be initiated. These are anticipated to take several weeks at minimum.

\section{Literature Cited}

Bevilacqua, P.C., Kierzek, R., Johnson, K.A., and Turner, D.H. 1992. Dynamics of ribozyme binding of substrate revealed by fluorescence-detected stopped-flow methods. Science 258:1355-1358.

Blount, K.F. and Tor, Y. 2003. Using pyrene-labeled HIV-1 TAR to measure RNA-small molecule binding. Nucl. Acids Res. 31:5490-5500.

Cate, J.H., Gooding, A.R., Podell, E., Zhou, K., Golden, B.L., Kundrot, C.E., Cech, T.R., and Doudna, J.A. 1996. Crystal structure of a group I ribozyme domain: Principles of RNA packing. Science 273:1678-1685.

Flynn-Charlebois, A., Wang, Y., Prior, T.K., Rashid, I., Hoadley, K.A., Coppins, R.L., Wolf, A.C., and Silverman, S.K. 2003. Deoxyribozymes with $2^{\prime}-5^{\prime}$ RNA ligase activity. $J$. Am. Chem. Soc. 125:2444-2454.

Gee, K.R., Archer, E.A., and Kang, H.C. 1999. 4Sulfotetrafluorophenyl (STP) esters: New watersoluble amine-reactive reagents for labeling biomolecules. Tetrahedron Lett. 40:1471-1474.

Golden, B.L., Gooding, A.R., Podell, E.R., and Cech, T.R. 1996. X-ray crystallography of large RNAs: Heavy-atom derivatives by RNA engineering. RNA 2:1295-1305.
Kierzek, R., Li, Y., Turner, D.H., and Bevilacqua, P.C. 1993. 5'-Amino pyrene provides a sensitive, nonperturbing fluorescent probe of RNA secondary and tertiary structure formation. J. Am. Chem. Soc. 115:4985-4992.

Millar, D.P. 1996. Fluorescence studies of DNA and RNA structure and dynamics. Curr. Opin. Struct. Biol. 6:322-326.

Mollova, E.T. 2002. Single-molecule fluorescence of nucleic acids. Curr. Opin. Chem. Biol. 6:823828.

Moore, M.J. and Query, C.C. 1998. Use of sitespecifically modified RNAs constructed by RNA ligation. In RNA-Protein Interactions: A Practical Approach (C.W.J. Smith, ed.) pp. 75-108. Oxford University Press, Oxford.

Moore, M.J. and Sharp, P.A. 1992. Site-specific modification of pre-mRNA: The 2'-hydroxyl groups at the splice site. Science 256:992-997.

Pan, T. 2000. Probing RNA structure and function by circular permutation. Methods Enzymol. 317:313-330.

Pan, T. and Uhlenbeck, O.C. 1993. Circularly permuted DNA, RNA and proteins; A review. Gene 125:111-114.

Preuss, R., Dapprich, J., and Walter, N.G. 1997. Probing RNA-protein interactions using pyrenelabeled oligodeoxynucleotides: $\mathrm{Q} \beta$ replicase efficiently binds small RNAs by recognizing pyrimidine residues. J. Mol. Biol. 273:600-613.

Silverman, S.K. and Cech, T.R. 1999a. Energetics and cooperativity of tertiary hydrogen bonds in RNA structure. Biochemistry 38:8691-8702.

Silverman, S.K. and Cech, T.R. 1999b. RNA tertiary folding monitored by fluorescence of covalently attached pyrene. Biochemistry 38:14224-14237.

Silverman, S.K. and Cech, T.R. 2001. An early transition state for folding of the P4-P6 RNA domain. RNA 7:161-166.

Silverman, S.K., Deras, M.L., Woodson, S.A., Scaringe, S.A., and Cech, T.R. 2000. Multiple folding pathways for the P4-P6 RNA domain. Biochemistry 39:12465-12475.

Sontheimer, E.J., Gordon, P.M., and Piccirilli, J.A. 1999. Metal ion catalysis during group II intron self-splicing: Parallels with the spliceosome. Genes \& Dev. 13:1729-1741.

Strobel, S.A. and Ortoleva-Donnelly, L. 1999. A hydrogen-bonding triad stabilizes the chemical transition state of a group I ribozyme. Chem. Biol. 6:153-165.

Walter, N.G., Hampel, K.J., Brown, K.M., and Burke, J.M. 1998. Tertiary structure formation in the hairpin ribozyme monitored by fluorescence resonance energy transfer. EMBO J. 17:23782391.

Whitaker, M. 2000. Fluorescent tags of protein function in living cells. BioEssays 22:180-187.

Young, B.T. and Silverman, S.K. 2002. The GAAA tetraloop-receptor interaction contributes differentially to folding thermodynamics and kinetics for the P4-P6 RNA domain. Biochemistry 41:12271-12276.
RNA Folding

Pathways

11.11.11 


\section{Key Reference}

Silverman and Cech, 1999b. See above.

Presents the derivatization and ligation approaches

to synthesizing pyrene-labeled P4-P6 RNA.

Contributed by Mary K. Smalley and

Scott K. Silverman

University of Illinois at

Urbana-Champaign

Urbana, Illinois

Site-Specific

Fluorescent Labeling of Large RNAs with Pyrene

11.11.12 